\title{
El Certificado Médico Prenupcial como política social (1936-1955)
}

\author{
The prenuptial medical certificate as social policy
}

\author{
Valeria Almirón ${ }^{1}$ \\ Carolina Biernat ${ }^{2}$
}

\section{Resumen:}

En el año 1936 se legisla en Argentina la obligatoriedad del certificado prenupcial para los varones como respuesta a las demandas de círculos profesionales, académicos y políticos en torno a la necesidad de dar respuesta a la escalada de los índices de morbilidad 'venérea' pero, también, al reclamo de diversos actores sociales respecto del reconocimiento de su derecho a la salud. El objetivo del trabajo es analizar el proceso de implementación de esta normativa como parte de la política social argentina. Para ello, consideramos al Estado como una esfera en la cual las distintas fuerzas políticas negocian, pactan o imponen sus conveniencias, y guarda en su interior un juego contradictorio de intereses que pueden generar relaciones conflictivas con otros actores de la sociedad civil y también con otras áreas administrativas. En este sentido, analizaremos los cuestionamientos a la política por parte de la comunidad médica $y$ las dificultades de orden presupuestario $y$ administrativo para su puesta en práctica, que llevaron a su reformulación durante los años del primer peronismo.

1 CeHCMe-UNQ

2 CeHCMe-UNQ-CONICET. Correo electrónico: cbiernat@yahoo.com 


\begin{abstract}
:
In 1936 the Argentinian State made obligatory the prenuptial certificate to men as answer to the demands of professional, academic and political circles. The object of this policy was based in the increase of the number of venereal morbidity and also as an answer to the claim of some actors for their health right. The goal of this paper is to analyze the process of implementation of this normative as part of the social policy in Argentina. For that we understand the State as a sphere where the different politic forces trade, pact and impose their retreats. Inside the State there is a contradictory game of interests that can generate conflictive relations with other actors of civil society and also other administrative areas. In addition, we will analyses the challenges to the policy by the medical community and the difficult with the economic resources for the application, that impulse the reformulation during the first Peronism.
\end{abstract}

Palabras clave: Matrimonio- enfermedad venérea- política social

Key words: Marriage - venereal disease - social policy

\title{
Introducción
}

El certificado médico prenupcial obligatorio para los varones fue incluido entre las disposiciones de la Ley 12331 de Profilaxis de las Enfermedades Venéreas, sancionada por el Congreso de la Nación Argentina el 17 de diciembre de 1936. Las resoluciones centrales de la normativa fueron la prohibición del establecimiento de casas o locales donde se ejerciera la prostitución o se incitara a ella, en clara oposición al sistema reglamentarista vigente hasta el momento, que permitía la habilitación de prostíbulos por parte de los municipios; la obligatoriedad de la denuncia del padecimiento de la enfermedad 'venérea' y de su tratamiento; el delito de contagio; la incorporación de la instrucción sexual en los planes de estudio de la educación formal; y la centralización administrativa de la prevención y el tratamiento de los males 'secretos' en todo el país. Para cumplir con este último objetivo se previó la creación, en el Departamento Nacional de Higiene, de una sección denominada Profilaxis de las Enfermedades 
Venéreas, a la que se le otorgaron como funciones el ejercicio de la superintendencia general y la coordinación de servicios venereológicos en hospitales, dispensarios, laboratorios de origen nacional, provincial, municipal o particular; la distribución económica y metódica de los medicamentos y el material de propaganda y divulgación científica; el estudio médico y social de las enfermedades; la organización del servicio de asistencia social y el desarrollo de la educación sexual, directamente o por medio de las entidades a quienes correspondiera llevar a cabo esta enseñanza (s/a, 1937).

La sanción y reglamentación posterior de la ley respondía a demandas que se venían expresando en los círculos de profesionales, en los ámbitos políticos y en las asociaciones de la sociedad civil del más variado orden, después del descubrimiento en la comunidad científica de que la sífilis era una enfermedad hereditaria, congénita y transgeneracional. Sus efectos, se creía, impactaban negativamente en la reproducción cuantitativa (mortalidad infantil, descenso del número de nacimientos por abortos y esterilidad) y cualitativa (enfermedades físicas y mentales) de la población, presente y futura. Esta constatación reforzaba la catalogación de las enfermedades 'venéreas' como sociales, en la medida en que no solo constituían un problema individual o afectaban a los sectores más desprotegidos. De allí que la intervención del Estado se hacía indispensable. No se trataba solamente de diagnosticar y curar una dolencia, sino de evitar la 'degeneración racial' de toda la nación que, de tener lugar, dejaría al país sin trabajadores, ciudadanos y soldados saludables, indispensables para su desarrollo productivo y para la construcción de su comunidad nacional.

Es en este punto donde la doctrina eugenésica, de creciente presencia en los ámbitos académicos, políticos e institucionales, venía a propiciar de marco teórico que legitimaba la demanda de intervención estatal. Sus seguidores, de las más variadas extracciones ideológicas y formación profesional, insistían en una legislación más amplia que asegurase la educación sexual de los futuros progenitores, formando su conciencia de reproductores 'responsables'; la instrucción profiláctica de aquellos que, cediendo a sus impulsos más viscerales, se pusieran en contacto con posibles focos de infección; la obligatoriedad del certificado prenupcial, a fin de identificar los casos de enfermos 'venéreos' y evitar las funestas consecuencias de su apareamiento para el 
'porvenir de la raza' y la asistencia pública a todos los que padecieran de una dolencia 'secreta' (Stepan, 1991; Miranda y Vallejo, 2005 y Biernat, 2005).

Pero la demanda de intervención estatal no solo persiguió el objetivo de garantizar una población saludable para la consolidación del mercado y la regeneración de la fuerza de trabajo sino, también, para la reproducción del sistema de dominación. Desde las primeras décadas del siglo XX se consolidó un discurso en torno a la 'cuestión social', que analizaba los efectos perniciosos sobre la sociedad y el orden público del proceso de modernización y su acentuación después de cada crisis mundial. Su objetivo central fue la integración de individuos y grupos a la organización social, a fin de evitar el conflicto o respondiendo a él, y tuvo como ejes principales de interés la pobreza, la marginalidad, la criminalidad, la salubridad, el hacinamiento habitacional y la conflictividad obrera. Paulatinamente, fue convirtiéndose en instrumento de presión a los poderes públicos y confluyó en el armado de la política social (Suriano, 2004; Zimmermann, 1995).

En este sentido, consideramos que la política de profilaxis 'venérea' -y dentro de ella el certificado prenupcial- fueron parte del proceso de configuración de la política social argentina. Así pues, entendemos por políticas sociales al conjunto de concepciones ideológicas, demandas sociales e intereses políticos y económicos que logran plasmarse en diseños normativos e institucionales y que buscan limitar las consecuencias de inequidad social producidas por las fuerzas del mercado y evitar la conflictividad que pueda resultar de ella. De este modo, sin cuestionarla, garantizan la reproducción de la sociedad de clases.

Nos interesa destacar que, paradójicamente, doctrinas tales como la eugenesia, el catolicismo social o el liberalismo reformista fueron útiles para erigir legitimidad política y para cargar de significado a lo que en la época era considerado como bienestar de la población. De allí que, además de disciplinar conductas y cuerpos, potenciaron las intervenciones sociales del Estado y el reconocimiento del derecho de la ciudadanía a la salud.

Partiendo de estas premisas, analizaremos el proceso de implementación del certificado prenupcial obligatorio para los varones como una política social. Para ello 
consideramos al Estado como un ámbito atravesado por una gran diversidad de intereses puestos en juego por los distintos actores sociales que luchan por su fracción de poder. Es decir, el Estado se presenta como una esfera en la cual las fuerzas políticas negocian, pactan o imponen sus conveniencias, y guarda en su interior un juego contradictorio de intereses que pueden generar relaciones conflictivas con otros actores de la sociedad civil y también con otras áreas administrativas. En este sentido, una política es un conjunto de acciones y de omisiones destinada a obtener determinados fines, pero, en el mismo proceso de implementación, se generan otras demandas que vuelven a interpelar a los diferentes actores sociales y políticos. La formulación e implementación de una política social es interpretada como el resultado o la síntesis de los múltiples intereses de tales actores. Esto nos permite entender cómo las normas, las reglamentaciones o los cambios en las atribuciones e injerencias de las agencias estatales de un período responden a relaciones sociales que expresan necesidades de un momento determinado.

Para identificar las relaciones conflictivas entre los actores de la sociedad civil y de la administración estatal y entre los que componían las distintas reparticiones oficiales y los diferentes niveles de gobierno encargados de implementar el certificado prenupcial obligatorio para los varones presentamos, en el primer apartado, las críticas de la corporación médica a los límites de la ley frente a las posibilidades materiales y jurídicas de su aplicación. En el segundo apartado nos centraremos en las resistencias de los gobiernos provinciales y municipales y en las limitaciones presupuestarias, administrativas y técnicas para hacer las pruebas de laboratorio en todo el territorio nacional. En el último apartado analizaremos los cambios introducidos durante el primer peronismo, fortalecimiento de la centralización administrativa de la repartición sanitaria, reconfiguración del marco normativo de la profilaxis 'venérea' y ampliación de los recursos materiales y profesionales, que llevaron a una mayor eficacia la puesta en práctica del certificado prenupcial para los varones y abrieron nuevos campos de demandas en torno a esta prueba sanitaria.

\section{Cuestionamientos de la corporación médica}


El artículo 13 de la Ley 12331 fue de gran relevancia para la lucha antivenérea porque significó por primera vez la intervención del Estado, en todo el territorio nacional, para brindar certificados médicos a los varones que se encontraban en los momentos previos al enlace matrimonial. Los galenos tenían el deber de efectuar el examen sin excepciones de ningún tipo, y los futuros esposos debían realizárselos, si querían casarse, y posponer su matrimonio en caso de probarse que se encontraban en período de contagio. Hasta ese momento, estos estudios eran efectuados, a quienes se prestaban voluntariamente, por médicos de servicios privados y consultorios prenupciales, asociaciones civiles que luchaban por la erradicación de las llamadas 'dolencias secretas' como, por ejemplo, la Liga Argentina de Profilaxis Social (Biernat, 2007). Pero, con la sanción de este artículo, y de manera global, de la ley, el Estado argentino puso en marcha una política sanitaria unificada de profilaxis 'venérea', que se proponía alcanzar a toda la población dentro de la frontera nacional para asegurar la reproducción saludable de trabajadores, ciudadanos y soldados, al tiempo que reconocía su derecho social a la salud.

Sin embargo, inmediatamente después de reglamentarse a través del Decreto 102466, del año 1937, comenzó a ser debatida por la comunidad de galenos. En este sentido, cabe recordar el peso de la opinión de los médicos en las decisiones de política sanitaria argentinas, en la medida que su proceso de profesionalización estuvo ligado a la necesidad del Estado de desarrollar su propia capacidad de intervención social por medio de la asistencia pública de los enfermos desde las últimas décadas del siglo XIX. En consecuencia, los médicos encararon su acción como agentes del Estado, uniendo su actividad a la de este, y como defensores 'naturales' de la salud de la población. Desde ese doble lugar de pertenencia se autopercibieron con una responsabilidad que iba más allá de prevenir y curar enfermedades, individuales y colectivas, y que residía en reflexionar sobre fenómenos sociales más generales y proponer posibles soluciones. En función de esta convicción hicieron sus diagnósticos, sugirieron medidas concretas y, al ocupar cargos en las agencias del Estado y en el Parlamento, gestaron acciones, con mejor o peor resultado, que buscaban tanto su mayor involucramiento en la esfera estatal como, al mismo tiempo, reforzar su papel en los ámbitos académicos, 
desarrollar su agremiación y conseguir potenciales clientelas privadas (Armus \& Belmartino, 2001: 301-325 y González Leandri, 2005: 133-150).

El primer punto de discusión de la puesta en práctica de la ley se centró en que solo podrían otorgar exámenes prenupciales aquellos directores y jefes médicos de servicios nacionales, provinciales o municipales de cualquier especialidad, junto con los galenos que las autoridades sanitarias determinasen (de la esfera militar o naval o incluso de la privada) en caso de que en la jurisdicción donde se encontrara el registro civil no hubiese instituciones públicas de salud. Si bien la potestad de los servicios públicos, en contraste con los consultorios privados, daba mayor transparencia a la emisión del documento probatorio del no padecimiento de un mal venéreo, el hecho de que cualquier especialista pudiera expedirlo provocaba recelos entre aquellos profesionales que desde principios de siglo venían trabajando en pos de la erradicación de las enfermedades 'secretas'. Tradicionalmente atendidas por dermatólogos o urólogos, estas enfermedades comenzaron a ser objeto de investigación y tratamiento de venereólogos y dermosifilógrafos. Estos nuevos expertos bregaron por un espacio en el campo académico, en el profesional y en el sistema sanitario, a través de la creación de cátedras en las universidades nacionales, de publicaciones específicas, de su incorporación en la asistencia de la salud de los distintos niveles de gobierno y en las nacientes reparticiones encargadas de la gestión de la profilaxis y tratamiento de las enfermedades venéreas. Paralelamente, reclamaron el reconocimiento oficial de la venereología y de la dermatosifilografía como especialidades de la medicina y el acceso a los cargos públicos a través de concursos probatorios de idoneidad y de experiencia previa del candidato en la materia (Biernat, 2007: 267).

En ese sentido José Luis Carrera, jefe de servicio del Hospital Fernández, insistía en que el certificado prenupcial debía ser expedido por un cuerpo de expertos y no por cualquier médico que poseyera "cierta categoría hospitalaria" (Carrera, 1939: 897). Lo que aparece en esta enunciación es la defensa corporativa hacia los especialistas en enfermedades venéreas como aquellos profesionales idóneos a la hora de extender un certificado de no padecimiento del mal, en detrimento de los médicos clínicos de los 
hospitales públicos que, si bien contaban con la prueba de laboratorio, podían dar lugar a erróneas lecturas por su falta de competitividad en el tema.

El segundo punto de discusión, y probablemente el más controversial, giró alrededor de la obligatoriedad del certificado médico prenupcial solo para el cónyuge de sexo masculino. Si bien el proyecto de Ley de Profilaxis de las Enfermedades Venéreas de 1936 incluía el certificado médico prenupcial obligatorio para el varón (realización de la prueba de wassermann) y la manifestación de no padecimiento de enfermedad venérea para la mujer mediante declaración jurada, durante su tratamiento en el recinto parlamentario quedó nula siquiera la posibilidad de que la mujer por propia voluntad solicitara estudios teniendo el deseo de saber su estado de salud. Esto se debió al rechazo por parte de la mayoría de los legisladores de "afectar el pudor de las damas" que se creía eran decentes y llegaban vírgenes al matrimonio, en contraste con las prostitutas, consideradas mujeres indecentes/deshonradas (Grammático, 2000). Las 'mujeres de mala vida' resquebrajaban los principios de la 'moral y las buenas costumbres' porque no solo desarrollaban su actividad en la esfera que no se correspondía con 'lo femenino' sino, sobre todo, porque eran consideradas el agente responsable de propagar el 'mal venéreo'.

Desde un análisis del fenómeno legal en clave de género, negar la posibilidad 'de saber' el estado de salud de las mujeres, sin dejar por ello de concebir tanto la implementación del certificado como de la declaración jurada como coercitiva y hasta invasiva del derecho individual de las personas e incluso íntimo de la pareja, no dejaba de encubrir una práctica de discriminación, opresión y subordinación hacia la mujer. Bajo esta óptica, era el varón quien le 'proporciona salud' tanto a la mujer como a la futura descendencia. Por lo tanto, la ley invisibilizaba al género femenino y lo despojaba de su condición de sujeto de derecho (Facio Montejo, 1992).

Sin hacer esta lectura, muchos miembros de la corporación médica reaccionaron reclamando que la mujer debía ser comprendida en las disposiciones del artículo 13, "tanto más en su carácter de madre que tiene funciones fundamentales en la reproducción de la especie" (Revista del Colegio de Médicos, 1938: 8), o al menos que se exigiera una declaración jurada de no padecimiento de enfermedad venérea en período de contagio. Desde el punto de vista legal, Enrique Díaz de Guijarro (1939), 
profesor de Derecho Civil en la Facultad de Ciencias Económicas de la Universidad de Buenos Aires, evidenció la arbitrariedad de imponer la obligatoriedad del certificado prenupcial a los varones, cuando la transmisión de las enfermedades era posible tanto por vía masculina como femenina. El argumento se reforzaba, para este médico legista, ante los enlaces de mujeres viudas o divorciadas en cuyo caso "no es posible esgrimir el efectista, pero inocuo argumento de que el examen prenupcial es un agravio a la honestidad de la mujer".

Esta posición, sostenida también por un importante número de médicos ligados a la asistencia venerológica que, en 1938, coincidieron en una encuesta en la necesidad de extender a las mujeres la obligación del certificado prenupcial o, al menos, de una declaración jurada de buena salud (Tey et al. 1938), encontró una opinión desfavorable por parte del Departamento Nacional de Higiene. Marcial Quiroga (1941), médico de la Sección Dermatovenerológica de esa repartición, sugirió que, en los casos de contagio conyugal y transmisión a la descendencia, la infección provenía generalmente del hombre.

Algunos especialistas redoblaron la apuesta y propusieron que el certificado no solo fuera obligatorio para ambos sexos, sino además que se convirtiera, ya sea por costumbre o legislación, en una suerte de intercambio de partes. Era tan importante saber con qué bienes contaban las familias de los novios, como si padecían 'taras sociales' alguno de sus integrantes, sobre todo los futuros esposos (Benthin, 1937).

En el otro extremo se encontraban aquellos que bregaban por el certificado prenupcial voluntario, afirmando que la obligación del examen hacía que numerosos varones no lo realizaran y, omitiendo la boda y formando parejas de hecho, sortearan a las autoridades médicas y a la posibilidad de quedar asentado un diagnóstico de enfermedad venérea. Teniendo la libertad de hacerlo de manera voluntaria, sería más cómodo y se volvería una costumbre higiénica inculcada en el pueblo (Di Liscia, 2002). En estas discusiones pueden advertirse que tanto las inclusiones como las exclusiones se desarrollan a partir de una dinámica histórica, lo que implica que el estatus de ciudadanía no se logra de una vez y para siempre y para un colectivo único y 'universal'. En este sentido, la entrada de marcas genéricas se constituye en un elemento preformativo y constitutivo de toda política social. Además, permiten pensar 
la política social como un campo que, si bien tiende a la inclusión, lleva consigo, al mismo tiempo, una lógica de exclusión, marginación y subordinación para las mujeres. Las diferentes temporalidades en las que se les reconocieron a las mujeres los derechos laborales, civiles y políticos dan cuenta de los límites existentes a la hora de pensar en el principio de igualdad dentro de la llamada república democrática (Biernat y Ramacciotti, 2012).

Un tercer foco de discusión giró en torno a casos excepcionales en los cuales la legislación había omitido opinión y los médicos creían necesario esclarecer cómo se debía proceder. Estos eran los matrimonios in artículo mortis; los casamientos en los cuales la esposa ya se encontraba embarazada y los convivientes que decidían legalizar su unión marital. En el primer caso, no estaba claro si era necesario realizar un examen médico al cónyuge teniendo en cuenta que uno de los dos se moriría antes de consumar el matrimonio, con lo cual no existía peligro de contagio venéreo (Nerio Rojas, 1937). Los otros dos casos eran más complicados porque esas parejas ya habían tenido relaciones sexuales, por lo cual, si en principio alguno de los dos había contraído el 'mal venéreo', el contagio ya se había producido y había traído o estaba en camino de hacerlo hijos al mundo. Los que ya habían nacido quizás estuviesen enfermos como sus padres, pero los que vinieran luego tendrían la posibilidad de nacer sanos si se curaba a los progenitores.

Finalmente, el 22 de noviembre de 1938 mediante una resolución del procurador del Tesoro Nacional, los casos de excepción fueron revisados, resolviendo omitir el certificado en los casos de matrimonio in artículo mortis, concubinatos en los que ya existiese descendencia, futuros esposos que al momento de contraer matrimonio no tuviesen un médico cercano que certificara la ausencia de padecimientos venéreos y uniones entre una menor embarazada, víctima de abuso, violación o rapto, y su victimario. A la resolución, se sumaría la postergación del matrimonio en los casos en los cuales se descubriera al marido enfermo en período de contagio (Silvetti, 1957).

El cuarto núcleo de debate se centró en la posibilidad de diagnósticos errados y la aparición de enfermedades de transmisión sexual una vez consumado el matrimonio. La falta de consultorios venerológicos y de laboratorios donde se pudiera hacer la prueba de Wassermann en muchos lugares del interior del país, como veremos en el 
apartado siguiente, llevaba a los médicos a preguntarse quién era el último responsable, el Estado o los galenos firmantes del certificado prenupcial, ante matrimonios autorizados mientras el varón se encontraba en periodo de contagio de la enfermedad venérea. En ese sentido, José Luis Carrera, Jefe de servicio en el Hospital Salaberry de la ciudad de Buenos Aires, afirmaba que la responsabilidad del examen prenupcial representaba "una preocupación más, de conciencia, para el médico". Pero, desgraciadamente, las leyes se aprobaban sin que el conjunto del cuerpo médico, y en particular de los especialistas a quienes afectaban, fueran consultados. De allí que se suscitaran, ulteriormente, "dudas, errores y malas interpretaciones" (Carrera 1938: 1999).

En consecuencia, para evitar la entrega de certificados después de un examen clínico o de reacciones sanguíneas insuficientes, los venereólogos sugirieron desde la asociación que los nucleaba que era menester estandarizar el proceso que debían seguir los diagnósticos y ajustarlo a los nuevos conocimientos de la disciplina (Massollo, 1937). En este sentido, Francisco Russo (1942) propuso que se modificara el texto de la ley disponiendo la creación de consultorios ad hoc para practicar los exámenes prenupciales, reglamentando cómo debían realizarse (análisis serológicos y bacteriológicos de rigor llevados a cabo en laboratorios oficiales) y documentando para cada sexo y estado civil sus resultados.

Por último, los profesionales juzgaban prudente que, por su relevancia, el artículo 13 fuese por sí mismo una ley. A pesar de que presentaba importantes falencias para constituirse en instrumento de lucha contras las 'dolencias secretas' y su aplicación era parcial, en definitiva, no dejaba de ser un paso importante en la profilaxis de las enfermedades infectocontagiosas en la población (Revista del Círculo Médico del Oeste, 1938: 397).

En suma, la sanción del certificado médico prenupcial gratuito y obligatorio para los varones, cristalizó el anhelo de los galenos por regular las uniones matrimoniales, al extremo de establecer quiénes podían -o no- casarse. No obstante ello, el texto de la ley y su puesta en práctica abrió nuevos reclamos de los médicos hacia las autoridades sanitarias. Por un lado, los intereses corporativos de los expertos en el tratamiento de las enfermedades venéreas, que deseaban ser reconocidos como los únicos idóneos 
para realizar diagnósticos y bregaban para estandarizar las pruebas previas al otorgamiento del certificado médico prenupcial. Por otro lado, las discusiones en torno a la obligatoriedad para la mujer del diagnóstico premarital, en las que los argumentos acerca de su inclusión o exclusión atravesaban un extenso arco de orden moral, médico y jurídico. En el medio, el intento de definición de una franja gris en la que quedaban atrapados un número importante de casos como los casamientos in artículo mortis, los matrimonios en los cuales la esposa ya se encontraba embarazada y los convivientes que decidían legalizar su unión marital, y mostraban que la realidad social trasvasaba los intentos de su regulación.

\section{Certificar en todo el territorio nacional ¿Un horizonte posible?}

A pesar de la gran controversia que trajo en los círculos médicos la sanción y la reglamentación de la Ley 12331 de Profilaxis de las Enfermedades Venéreas, y de lo arduo que se tornaba interpretar determinados artículos que dejaban a criterio de los galenos su proceder, en lo que atañe a las disposiciones del artículo 13, hacia los últimos años de la década del treinta, la sección Dermatovenerológica del Departamento Nacional de Higiene, repartición facultada por dicha ley para llevar a cabo la profilaxis venérea, comenzó una intensa campaña en pos de la implementación del certificado prenupcial en todo el territorio nacional.

Como ha sido demostrado en otro trabajo, volver de alcance nacional una política sanitaria, a pesar de estar contemplado en el texto de la normativa, fue uno de los mayores desafíos que debió afrontar el Departamento Nacional de Higiene desde su creación en 1880. El régimen federal, establecido por la Constitución Nacional, les otorgaba a las provincias total autonomía respecto de sus intervenciones sanitarias y las dejaba con un margen de discusión muy alto con la repartición central. Situación que se trasladaba, además, a los municipios, fundamentalmente a aquellos con muchos recursos o que competían jurisdiccionalmente con el Departamento Nacional de Higiene como, por ejemplo, la ciudad de Buenos Aires con su Dirección de la Asistencia Pública, ungida de funciones sanitarias. Esta situación daba como resultado la constante superposición de atribuciones y una indefinición de jerarquías de las distintas reparticiones sanitarias de carácter nacional y local que, en la práctica, restringían el 
territorio de intervención del organismo sanitario nacional a los puertos y a los territorios nacionales (Biernat, 2015).

No obstante ello, en el caso de la política de profilaxis venérea y a diferencia de otras políticas sanitarias, el relativo éxito de su puesta en práctica y la sumisión de los distintos niveles de gobierno y de las instituciones de la órbita privada a las directivas de la repartición central, pueden explicarse por la función exclusiva del Departamento Nacional de Higiene, otorgada por la Ley 12331, de comprar y distribuir económica y metódicamente los medicamentos por él recomendados para seguir los tratamientos, a todos los dispensarios antivenéreos, incluidos los de los institutos penales. Las drogas, liberadas de todo impuesto aduanero en caso de importación y de aranceles internos en caso de fabricación, eran adquiridas por las autoridades sanitarias centrales con su propio presupuesto y distribuidas según las necesidades de cada provincia e institución sanitaria. En suma, esta triple prerrogativa del departamento de imponer un tratamiento estandarizado para las enfermedades venéreas, decidir acerca de aquellos medicamentos que debían ser liberados de las obligaciones impositivas y distribuirlos en todo el país, le confirió la capacidad de centralizar la lucha antivenérea y la obtención de razonables resultados (Biernat, 2007).

En las memorias anuales de la Sección Dermatovenerológic, cinco parecen haber sido las preocupaciones de las autoridades nacionales respecto al examen prenupcial. En primer lugar, su aceptación por parte de la población en general. Según los informes y estadísticas brindados por la repartición, no existía la resistencia supuesta antes de llevar a la práctica la disposición del certificado prenupcial obligatorio y la opinión pública parecía consensuar el "valor sanitario y moral implícito en esta medida" (Departamento Nacional de Higiene, mayo 1939: 239-241). En contraste con esta apreciación, en un informe publicado por la Revista Argentina de Dermatosifilología se presentaba un panorama poco favorable. Los galenos Antenor Tey, Rafael Garzón y Gustavo Brandan (1938) exponían los resultados de las encuestas realizadas por ellos mismos en los espacios provinciales y remarcaban que en muchas regiones la población aún no estaba preparada culturalmente para el cambio y continuaba enraizada en las viejas costumbres. 
En segundo lugar, el temor a la disminución de la celebración de nuevos matrimonios y el incremento de nacimientos 'ilegítimos' fueron desmentidos por las cifras estadísticas presentadas por el Departamento Nacional de Higiene. De esta forma, la repartición nacional, respondía a las denuncias de referentes del mundo católico, como el intelectual Alejandro Bunge y el arzobispo de Buenos Aires, monseñor Franceschi, quienes afirmaban que las supuestas trabas burocráticas del certificado médico prenupcial incentivarían el nacimiento de hijos 'ilegítimos' porque la población se negaría a contraer matrimonio. En consecuencia, estos niños nacerían en inferioridad de condiciones respecto a los hijos 'legítimos', por encontrarse en contra de "los conceptos de la familia cristina, la naturaleza humana y el ámbito hogareño" (Di Liscia, 2002: 215).

En tercer lugar, un punto central en la agenda del Departamento Nacional de Higiene fue la instalación de consultorios prenupciales a lo largo de todo el territorio nacional. A pesar de las cifras y del carácter triunfalista que se constata en los documentos oficiales, estudios realizados recientemente acerca de la llegada que el Estado nacional tenía en las provincias del interior, en especial en los territorios nacionales, muestran que la atención sanitaria era deficiente al punto de que muchas maestras e incluso policías locales terminaban ocupando la función del médico. Desde Buenos Aires no solo no se suministraban recursos, sino que tampoco se enviaban grupos de profesionales idóneos que pudieran atender a la población aislada de los centros urbanos (Bohoslavsky y Di Liscia, 2008). Ante esta falta de recursos y de personal idóneo, la repartición sanitaria instaló dispensarios de atención primaria en muchas zonas del país, donde los médicos generalistas otorgaban los certificados prenupciales (Sussini, 1938; Puente, 1940).

En cuarto lugar y vinculado a los temas de falta de personal e infraestructura, la sección Dermatovenerológica debió afrontar la dificultad de realizar los análisis serológicos en lugares que no poseían laboratorios o que estaban muy alejados de ellos. Con este fin, realizó gestiones ante la Dirección General de Correos y Telégrafos para remitir gratuitamente por vía aérea, desde zonas alejadas como la Patagonia, las extracciones a ser analizadas por el Instituto Bacteriológico Nacional. Por otro lado, proyectó la creación, hasta el año 1942 sin resolución práctica, de laboratorios 
regionales ubicados en lugares estratégicos del territorio destinados a servir a sus respectivas zonas de influencia, y donde los materiales a examinar pudieran llegar por ferrocarril u otros medios de movilidad dentro de las 24 horas de haber sido extraídos (Departamento Nacional de Higiene, 1939; 1940; 1941; 1943).

Por último, la sección Dermatovenerológica, se propuso organizar un sistema de estadísticas para registrar los aspectos cuantitativos ligados a la profilaxis venérea en todo el territorio del país. Para el director de la repartición, la Ley 12331 constituía una división de aguas respecto de la posibilidad de llevar a cabo estos registros, en la medida que incluía el tema en la agenda sanitaria como un problema de orden nacional. Para el funcionario, la obra profiláctica que se realizaba, si bien estimable, adolecía de la falta de coordinación con otros centros antivenéreos de jurisdicción nacional, provincial, municipal o particular, ya que se carecía de un instrumento legal que la autorizara (Puente, 1940). No obstante ello, las estadísticas devinieron, a la vez, en fuente de legitimación para la política de profilaxis nacional y en objeto de resistencia por parte de las provincias, que se negaban a entregar los datos solicitados como una forma de contrarrestar los efectos de la centralización administrativa (Daniel, 2012).

En suma, la puesta en práctica del certificado prenupcial durante los años de entreguerras, a pesar de no contar, como otras políticas sanitarias, con la oposición abierta de los poderes locales, se vio sometida a una resistencia más sutil como, por ejemplo, la de la negativa de entregar datos estadísticos por pare de las autoridades provinciales y municipales a la repartición nacional. Por otro lado, las limitaciones más importantes fueron la falta de presupuesto, de personal idóneo y la imposibilidad de contar con la infraestructura necesaria para hacer las pruebas de laboratorio en todo el territorio nacional.

\section{Centralizar y curar}

La posibilidad de implementar el certificado médico prenupcial como una política de alcance nacional, se reforzó a partir de los primeros años de la década de 1940 en la medida que la repartición sanitaria fue sometida a un conjunto de cambios escalonados que fortalecieron su centralización administrativa. En octubre de 1943, 
un decreto del gobierno militar de Edelmiro Farrel estableció la creación de la Dirección Nacional de Salud Pública y Asistencia Social bajo la tutela del Ministerio del Interior. La normativa apuntaba a la unificación entre los servicios sanitarios y los asistenciales, intentaba romper con el subsidio estatal a las instituciones particulares e imponía a las provincias y municipios acuerdos de "coordinación" de sus políticas con la repartición nacional. En este sentido, la política de profilaxis venérea parece haber ido más allá de las posibilidades que la nueva repartición sanitaria poseía para subordinar a los poderes locales. Haciendo uso de la prerrogativa que la Ley 12331 le había conferido de distribuir económica y metódicamente en todo el territorio las drogas para la cura de las enfermedades de transmisión sexual, el director general de Salud Pública y Asistencia Social, Eugenio Galli, ordenó no proveer medicamentos a los municipios 'ricos' como, por ejemplo, la ciudad de Buenos Aires. La medida se fundamentaba en que la municipalidad poseía recursos materiales suficientes, por lo que no necesitaba de la colaboración del presupuesto nacional para llevar a cabo la profilaxis venérea (Baliña, 1945).

La ambición centralizadora de la repartición nacional duró tan solo diez meses. El 16 de agosto de 1944, por Decreto 21901, se produjo una nueva división entre los servicios sanitarios y los asistenciales. Mientras los primeros siguieron bajo la órbita de la Dirección Nacional de Salud Pública, los segundos pasaron a depender de la Secretaría de Trabajo y Previsión. La reconfiguración de la cartera sanitaria y la sanción de su decreto reglamentario de la actividad (1589/44) supuso el diseño de un modelo de relaciones interjurisdiccionales entre la nación y las provincias un poco mejor definido. Se estableció como esfera de acción de la Dirección a todo el territorio de la nación, se formalizaron los acuerdos como estrategia para compatibilizar el ejercicio por parte de las provincias de sus atribuciones en salud pública y se determinó que la nación asignaría una ayuda federal para "Obras y Servicios" de las administraciones provinciales, a condición de que estas se adecuaran a una serie de requisitos. La novedad pareció estar centrada en la posibilidad de la repartición nacional de disponer de un mayor presupuesto para que la coordinación de esfuerzos inclinase los platillos de la balanza a su favor (Biernat, 2015). 
Con todo, la centralización administrativa definitiva de la cartera sanitaria debió esperar al período peronista. En 1946, fue creada la Secretaría de Salud Pública bajo la órbita de la Presidencia, abandonando su filiación del Ministerio del Interior, en búsqueda de una mayor autonomía en la gestión administrativa y en el manejo de cuentas. Finalmente, en 1949 se organizó el Ministerio de Salud Pública, pero esta nueva jerarquía no significó una mayor autonomía para su funcionamiento porque fue disputado su campo de acción y su presupuesto por una nueva institución de objetivos sociales promovida por el gobierno: la Fundación Eva Perón (Ramacciotti, 2009).

Respecto de la profilaxis venérea, la gestión del gobierno peronista resolvió la modificación y la complementación de la reglamentación de la Ley 12331 basada en el diagnóstico de que era necesario implementar los instrumentos legales y técnicos que permitieran "una vigilancia más precisa y una exacta ubicación de los focos por parte de la autoridad sanitaria" (s/a, 1946). De allí que el decreto 9863, firmado en septiembre de 1946, estableció que las enfermedades venéreas serían tratadas con el mismo criterio sanitario que cualquier otra afección infectocontagiosa y que los pacientes serían sometidos a las medidas generales que se adoptaban con todas las enfermedades transmisibles de acuerdo a la Ley 12317. Los instrumentos previstos para luchar contra estos males fueron la educación sanitaria, destacando las ventajas de la profilaxis individual; la denuncia y tratamiento obligatorios de los enfermos; la investigación de la fuente de contagio -en especial las prostitutas-; la creación de un Instituto de Higiene Social para la internación de los pacientes; penas específicas para todos aquellos que ignoraran la ley, incluidos los médicos, y la fundación de nuevas dependencias para reunir estadísticas, para controlar el cumplimiento de la ley -policía sanitaria- y para formar al personal técnico especializado -investigadores sociales y venereólogos. Los costos de los nuevos servicios serían financiados por los impuestos obtenidos de los casinos de Mar del Plata, Miramar y Necochea (s/a, 1946).

Este sesgo más represivo, pero también más inclusivo -en la medida que la política sanitaria se convirtió en uno de los pilares del despliegue de la política social del primer peronismo- de la lucha oficial antivenérea, fue consensuado por la comunidad médica. Así, por ejemplo, Eduardo Glantz y Héctor González (1948), médicos del Hospital San Roque de la ciudad de Mendoza, propusieron en las Primeras Jornadas 
Venerológicas Argentinas, realizadas en Buenos Aires en noviembre de 1946, la creación de un registro serosifilográfico nacional a fin de descubrir las enfermedades venéreas llamadas 'encubiertas', por ser ignoradas por las personas que las padecían. Sugirieron que los exámenes fueran obligatorios para los conscriptos, los miembros de las fuerzas armadas, la gendarmería y la policía, los empleados del Estado en todos sus niveles, los enfermos internados en los hospitales o concurrentes a sus consultorios externos y optativos para el resto de la población.

La Secretaría de Salud Pública, a cargo del neurocirujano Ramón Carrillo, incluyó como prioritaria en su agenda la lucha contra los males venéreos. Partiendo de cifras bastante altas de "casos nuevos" por año, 47400 de sífilis y 30200 de blenorragia, propuso en el Plan Analítico de Salud Pública para los primeros cinco años de gestión de esta repartición, una serie de medidas entre las que se encontraban el examen prenupcial voluntario para varones y mujeres, como "gesto patriótico"; la organización de una campaña de educación pública de gran alcance; la instalación de centros de higiene social en todo el país; el tratamiento masivo, teniendo en cuenta los adelantos de la medicina que permitían la cura a través de la penicilina, y la prevención de la prostitución a través de la creación de reformatorios y asilos para quienes ya desempeñaban esta actividad y la protección de menores en riesgo de ejercerla (Secretaría de Salud Pública, 1947).

Más allá de los términos propositivos de la política sanitaria, la Dirección de Higiene Social, organismo responsable de la profilaxis venérea dentro de la Secretaría de Salud Pública, organizó su labor alrededor de dos ejes: la educación sanitaria y la implementación de un nuevo tratamiento para las enfermedades venéreas basado en el suministro de penicilina, arsénico y bismuto. Según los especialistas, la combinación de estas drogas limitaba enormemente en el tiempo el período del tratamiento. El único requisito para su éxito era la provisión continuada de medicamentos a todos los servicios de carácter nacional, provincial, municipal y privado (Dirección de Higiene Social, 1948).

El gobierno peronista cumplió con el abastecimiento adecuado de dichas drogas, en especial de penicilina, cuya disponibilidad dependía del mercado externo, y cuya producción había sido monopolizada por la firma norteamericana Squibb en el año 
1947. La fábrica abrió sus puertas en 1949, con una producción de 51000 unidades anuales, casi el doble de la cantidad mínima establecida por el contrato. Gracias a ello, después de 1949 fue posible expandir el control de los males venéreos de un modo renovado y significativo (Campins y Pfeiffer, 2004).

El certificado prenupcial no solo fue considerado un elemento central en la profilaxis venérea, sino también un instrumento de medición y construcción estadística. En este sentido, los informes del Ministerio de Salud Pública (1952) aseguraban que su cumplimiento se había extendido a todas las reparticiones sanitarias del país. Este nivel de acatamiento entendemos que estuvo vinculado con la creciente centralización administrativa de la repartición sanitaria, pero, también, con una mayor disponibilidad de recursos monetarios, técnicos y profesionales. Por otro lado, los informes presentados cruzaban el número de certificados otorgados por año con la cantidad de enfermos infectados. La cantidad de certificados denegados había descendido de 1 , 13\% en 1946 a 0,75\% en 1951, lo que para el Ministerio de Salud Pública confirmaba que el índice de morbilidad venérea se había reducido gracias al éxito de su política de profilaxis. Cabe aclarar que muchos informes médicos de hospitales públicos llegaban a las mismas conclusiones que la repartición nacional, lo que podría ser leído como la confirmación de una tendencia de descenso de las enfermedades de origen sexual (Padilla y Speroni, 1951).

Por su parte, la reflexión de médicos de la esfera estatal provincial, como el doctor tucumano Luis Manuel Silvetti (1957), jefe de la división Laboratorios de la dirección Regional de Sanidad del Norte y ministro de Asistencia Social y Salud Pública, reconocía el gran provecho que representaba para la profilaxis 'venérea', la aplicación del certificado prenupcial, a pesar de las dificultades de su aplicación para su provincia. Uno de los puntos interesantes referidos al examen prenupcial fue la revitalización de un debate que había quedado en suspenso durante los años 30. Como ya hemos mencionado, la Secretaría de Salud Pública introdujo el tema en el Plan Analítico de Salud de 1947, consignando que la prueba fuese voluntaria para varones y mujeres y se pidiese como "gesto patriótico". En este sentido, la ampliación de la ciudadanía social para mujeres y varones parecía conllevar a una serie de responsabilidades para con el Estado. 
Pero no solamente el Estado tomó la iniciativa en este terreno, la propia comunidad médica se involucró en la discusión. Las encuestas realizadas a mujeres en el Hospital Ignacio Corsini y leídas en la Academia Nacional de Medicina el 30 de agosto de 1951 por los galenos Padilla y Speroni arrojarían los siguientes resultados: de un total de 81 empleadas de escritorio, 78 (96\%) estaba de acuerdo con que se las incluyera en la ley, mientras que 3 (4\%) estaban en desacuerdo. De un total de 95 obreras, 90 (94\%) de ellas estaba de acuerdo con que se las incluyera, mientras 5 (6\%) estaba en desacuerdo. (Padilla y Speroni, 1951)

Esta nueva tendencia a incluir la opinión de las mujeres de manera directa, buscando saber qué pensaban, muestra no solo la vuelta a un debate que parecía haberse quedado en el pasado, sino, sobre todo, la presión porque se certificase a las mujeres, teniendo en cuenta que la gran mayoría estaba a favor. No es casualidad la selección realizada, sobre todo de las empleadas de escritorio de gran reputación dentro de las trabajadoras, quienes se sabe que volverían a la esfera pública una vez casadas (Queirolo, 2008).

En suma, durante el primer peronismo, la puesta en práctica del certificado prenupcial devino en una disposición más eficaz en la medida que la repartición sanitaria fue sometida a un conjunto de cambios escalonados que fortalecieron su centralización administrativa y que se contó con mayor cantidad de recursos materiales, personal idóneo e infraestructura. Por otro lado, el certificado comenzó a ser visto no solo como un derecho de la población, sino como una responsabilidad para con la sociedad en su conjunto. De allí que la obligación de las mujeres de probar estar libres de alguna enfermedad de origen sexual antes de llegar al matrimonio volvió a aparecer en la escena de discusión.

\section{Conclusiones}

En los años treinta se constituyeron nuevas agencias estatales que redefinieron muchas relaciones cruciales dentro de la sociedad civil, aun aquellas que se encontraban tradicionalmente ceñidas al ámbito de lo privado. En el área de las políticas sanitarias, esa intervención se basó en los supuestos técnico-organizativos de los médicos. Utilizando sus antiguas redes de inserción profesional y política, estos expertos 
obtuvieron un acentuado protagonismo en la esfera estatal. Dos tópicos fueron recurrentes en su agenda: la necesidad de dotar al Estado de una organización centralizada y racional de la asistencia médico-social y la resolución de la llamada "crisis poblacional", caracterizada por un decaimiento en los índices de natalidad, principalmente en las zonas prósperas, y un empobrecimiento biológico de la población. Sobre estos dos pilares el Departamento Nacional de Higiene sufrió una reorganización administrativa. La obtención de nuevas atribuciones y la sanción de leyes parlamentarias legitimaron aún más el lugar ocupado por estos especialistas en la esfera pública a partir de las reformas que propusieron.

Las enfermedades venéreas fueron uno de los temas centrales abordados por la repartición sanitaria. Por un lado, la lectura alarmista respecto de la creciente cantidad de infectados, de las consecuencias genéticas para la salud de la población que el mal traería y de sus repercusiones en el desarrollo productivo y en la construcción de la comunidad nacional, pusieron en evidencia la necesidad de una urgente e idónea intervención. En este sentido, la salud fue entendida como uno de los componentes esenciales del 'bienestar. de la población y, en virtud de ello, constituyó uno de los ejes en torno de los cuales se articuló la política social.

Por otro lado, estaba claro que, para conseguir óptimos y rápidos resultados, debía apelarse a una acción coordinada y de relativo monopolio de autoridad. El Departamento Nacional de Higiene se propuso, entonces, centralizar la prevención y el tratamiento de los 'males secretos'. Para ello, contó con una ley nacional que creó y dotó de atribuciones y recursos a una de sus divisiones, la sección Dermatovenerológica. Creemos que el verdadero éxito de esta política sanitaria, lejos de ser medido en términos de disminución de las dolencias venéreas -hacerlo significaría repetir la versión triunfalista de las parciales e incompletas estadísticas confeccionadas por la propia repartición- se vincula con su capacidad de imponer autoridad por encima de los niveles de asistencia regional y privada. Este logro estuvo asociado a su prerrogativa de administrar el presupuesto, distribuir los medicamentos e imponer un tratamiento estandarizado.

El certificado prenupcial obligatorio y gratuito para los varones fue uno de los instrumentos centrales de la profilaxis venérea. No obstante haber sido legislado y 
reglamentado, su puesta en práctica llevó a una serie de debates entre las agencias estatales y distintos actores, tales como la corporación médica, intelectuales, profesionales, la jerarquía eclesiástica y los propios destinatarios, quienes se aliaron o se enfrentaron en torno a intereses que, si bien podían no estar en línea directa con sus expectativas, propiciaron un espacio de negociación para otras demandas y reclamos o crearon un escenario para mantener el orden social. De este modo, las posiciones que se asumieron en el proceso de resolución de cuestiones vinculadas a los intereses en pugna definieron tanto la naturaleza de su intervención social como la consecuente inclusión de determinados núcleos poblacionales y la marginación de otros.

En este sentido, la oportunidad de acceso a la salud para los varones de las clases más desprotegidas no corrió en paralelo con el reconocimiento de este derecho a las mujeres, por considerar que los resultados de la prueba requerida para el otorgamiento del certificado prenupcial podrían afectar su 'honra' y que era el varón el que aseguraba la salud de la mujer 'decente'. De todos modos, estos principios contenidos en la normativa abrieron lugar a cuestionamientos que se legitimaron desde criterios sanitarios, sociales y hasta cívicos.

Un segundo conjunto de límites a la puesta en práctica del certificado prenupcial para los varones lo constituyó la desproporción entre la ambición de intervención de la normativa en todo el territorio nacional y la resistencia de los poderes provinciales y municipales y la escasez de recursos, personal idóneo y tecnología para llevarlo a cabo. La posibilidad de sortear estas dificultades se dio en consonancia con la reorientación de los objetivos políticos a lo largo de la década de 1940. En efecto, para el Estado peronista la política sanitaria se constituyó en una de las más visibles intervenciones sociales. En consecuencia, la multiplicación del presupuesto para la profilaxis venérea, el cariz más represivo -pero a la vez más inclusivo- de los instrumentos ligados a ella, la profundización del proceso de centralización administrativa de la agencia sanitaria nacional por sobre las provinciales y municipales y el avance de los desarrollos tecnológicos, como, por ejemplo, el uso de la penicilina o la complejización de las pruebas de laboratorio sentaron las bases para que la obligación del certificado prenupcial fuese posible desde el lado de la oferta de este servicio por parte del Estado. 
Por último, en los casi ochenta años de existencia de la llamada Ley de Profilaxis de las Enfermedades Venéreas, dos modificaciones importantes se impusieron respecto del certificado prenupcial. Por un lado, la Ley 16668, sancionada en el año 1965, incluyó a las mujeres en la obligatoriedad de obtener el certificado médico prematrimonial si deseaban casarse. Sin embargo, esa conquista del derecho que obtuvieron las mujeres (decentes), como habían deseado los galenos que abogaban por su incorporación, quedó atada a otra disposición que, dentro de la Ley 12331, condenaba a las "otras mujeres" (las indecentes). El artículo 15 constituyó el marco legal desde el que se intensificaron las persecuciones a las mujeres que ejercían y ejercen el trabajo sexual. Con los años, el estigma social se acrecentó involucrándolas en delitos como la corrupción policial y el narcotráfico. Por otro lado, el nuevo Código Civil y Comercial argentino, en vigencia desde agosto de 2015, prevé la anulación del requisito del certificado prenupcial para contraer matrimonio.

\section{Bibliografía}

Armus, Diego y Belmartino Susana (2001). Enfermedades, médicos y cultura higiénica. En: Cattaruzza, Alejandro (Dir.). Crisis económica, avance del Estado e incertidumbre política (1930-1943) pp. 285-329. Nueva Historia Argentina, Tomo 7, Buenos Aires: Sudamericana.

Baliña, Pedro (1945). Incremento de la sífilis reciente. Perspectivas desfavorables. Información suministrada a las autoridades sanitarias. Revista Argentina de Dermatosifilología, 1, 107-112.

Benthin, Walther (1937). El certificado prenupcial. Más que la atracción mutua, la salud debe ser la base de la unión matrimonial. De ahí la importancia del examen médico previo. Viva Cien Años, IV, 1, 8.

Biernat, Carolina (2005). La Eugenesia argentina y el debate sobre el crecimiento de la población en los años de entreguerras. Cuadernos del Sur (Historia), 34, 251-273.

Biernat, Carolina (2007). Médicos, especialistas, políticos y funcionarios en la organización centralizada de la profilaxis de las enfermedades venéreas en la Argentina (1930-1954). Anuario de Estudios Americanos, 64, 1, 257-288.

Biernat, Carolina y Ramacciotti, Karina (2012). Preguntas y herramientas para el análisis de las políticas sociales. En: Carolina Biernat y Karina Ramacciotti (Eds.) La política social entre demandas y resistencias. Argentina, 1930-1970 (pp. 9-36). Buenos Aires: Biblos. 
Biernat, Carolina (2015). El proceso de Centralización del Departamento Nacional de Higiene (1880-1944). En: Carolina Biernat, Juan Manuel Cerdá y Karina Ramacciotti (Dirs.), La salud pública y la enfermería en la Argentina (pp. 47-84). Buenos Aires: Universidad Nacional de Quilmes Editorial.

Bohoslavsky, Ernesto y Di Liscia, María Silvia (2008). La profilaxis del viento. Instituciones represivas y sanitarias en La Patagonia Argentina, 1880-1940. Asclepio, 2, 187-206.

Campins, Mónica y Pfeiffer, Ana Teresa (2004). La producción de medicamentos durante el peronismo y el conflicto con los laboratorios Massone. ¿Problema tecnológico o político? Ciclos, 27, 123-151.

Carrera, José Luis (1938). El certificado médico prenupcial en relación con la sífilis. La Semana Médica, 12, 218.

Carrera, José Luis (1939). El examen médico prenupcial: ¿Qué guías ha de tener el médico para permitir el matrimonio, o no, bajo el punto de vista de la infección sifilítica? Revista Argentina de Dermatosifilogía, XXII, 199.

Daniel, Claudia (2012). Contar para curar: estadísticas y comunidad médica en Argentina, 1880-1940. História, Ciências, Saúde-Manguinhos, 19, 89-114.

Dirección de Higiene Social (1948). Actividades técnicas de la Dirección de Higiene Social durante el mes de octubre de 1948. Archivos de la Secretaría de Salud Pública de la Nación, IV, 5, 479.

Díaz de Guijarro, Enrique (1939). Eugenesia y Matrimonio. Revista de Medicina Cancerología, XIII, 130, 20-26.

Departamento Nacional de Higiene (1939-1943). Boletín Sanitario. Buenos Aires.

Di Liscia, María Silvia (2002). Hijos sanos y legítimos: sobre matrimonio y asistencia social en Argentina (1935-1948). História, Ciências, Saúde- Manguinhos, 9 (Suplemento): 209-232.

Garzón, Rafael (1955). El certificado médico prenupcial su importancia médico-sanitaria. Revista de la Facultad de Ciencias Médicas de Córdoba, XIII, 1, 36.

Glantz, David y González, Héctor (1948). El registro serosifilográfico de la nación. Revista de la Sociedad Argentina de Venerología y Profilaxis Social, XII, 21, 43-51.

González Leandri, Ricardo (2005). Madurez y poder. Médicos e instituciones sanitarias en la Argentina a fines del siglo XIX. Entrepasados, 27, 133-150 
Gramático, Karin (2000). Obreras, prostitutas y mal venéreo (Un Estado en busca de la profilaxis). En: Fernanda Gil Lozano, Valeria Pita y María Ini (Comps.) Historia de las Mujeres en la Argentina (pp. 117-135). Tomo II. Buenos Aires: Siglo XXI.

Facio Montejo, Alda (1992). Cuando el género suena cambios trae (Una metodología para el análisis de género del fenómeno legal). San José de Costa Rica: Ilanud.

Massolo, Orestes (1937). Al margen del certificado médico prenupcial. Revista de la Sociedad Argentina de Venerología y Profilaxis Social, I, 2, 151-154.

Ministerio de Salud Pública de la Nación (1952). Memoria correspondiente al período junio de 1946 a mayo de 1952. Buenos Aires.

Marisa Miranda y Gustavo Vallejo (Coms.) (2005), Darwinismo social y eugenesia en el mundo latino. Buenos Aires: Editorial Siglo XXI.

Padilla, Tiburcio y Speroni, Alberto (1951). Diez años de examen médico prenupcial. Revista de la Academia de Medicina, XI, 5, 283-287.

Puente, José (1940). Estado actual de la profilaxis de las enfermedades venéreas en la República Argentina. Boletín Sanitario del Departamento Nacional de Higiene, IV, 1, 15.

Queirolo, Graciela (2008). El mundo de las empleadas administrativas: perfiles laborales y carreras individuales (Buenos Aires, 1920-1940). Trabajos y Comunicaciones, 34, 129151.

Quiroga, Marcial (1941). Certificado Prenupcial. Boletín Sanitario del Departamento Nacional de Higiene, 7, 759-761.

Ramacciotti, Karina (2009). La política sanitaria del peronismo. Buenos Aires: Biblos.

Revista del Circulo Médico del Oeste (1938). Examen prenupcial, VI, 78, 397.

Rojas, Nerio (1937). Crítica médico-legal de las últimas leyes profilácticas. Delito de contagio venéreo. Certificado pre-nupcial. Secreto médico. Curanderismo. El Día Médico, IX, 21, 370-372.

Russo, Francisco (1942). La reforma de la Ley 12331. Revista de la Sociedad Argentina de Venerología y Profilaxis Social, V, 8, 839-844.

s/a (1937). Legislación Sanitaria. Boletín Sanitario del Departamento Nacional de Higiene, I, 1-12, 32-40.

s/a (1946). Reglamentó el Poder Ejecutivo la ley de Profilaxis Social. Revista de la Sociedad Argentina de Venerología y Profilaxis Social, X, 18, 45-57. 
Secretaría de Salud Pública (1947). Plan Analítico de Salud Pública, Tomo II, Buenos Aires, 979-1018.

Silvetti, Luis Manuel (1957). Comentarios sobre el certificado prenupcial a casi 20 años de su vigencia. Archivos Argentinos de Dermatología, VII, 1, 4-5.

Suriano, Juan (2000). Una aproximación a la definición de la cuestión social en Argentina. En: Juan Suriano (Comp.) La cuestión social en Argentina 1870-1943 (pp. 129). Buenos Aires: Biblos.

Sussini, Miguel (1938). Organización de la profilaxis de las enfermedades venéreas en la República Argentina (Informe presentado al X conferencia Sanitaria Panamericana). Boletín Sanitario del Departamento Nacional de Higiene, II, 10, 753- 754.

Stepan, Nancy (1991). The Hour of Eugenics. Race, Gender and Nation in Latin America. Ithaca and London: Cornell University Press.

Tey, Antenor; Garzón, Rafael y Brandan, Gustavo (1938). Informe presentado por la subcomisión del Círculo Médico de Córdoba (A propósito de la ley 12331 de profilaxis de las enfermedades venéreas. Revista Argentina de Dermatosifilología, XXII, 168-172.

Zimmermann, Eduardo (1995). Los liberales reformistas. La cuestión social en la Argentina. 1890-1916. Buenos Aires: Sudamericana. 